\title{
Photodegradation of Polymer-dispersed perylene di-imide dyes
}

\author{
Nobuaki Tanaka, ${ }^{\mathrm{a}}$ Nikolay Barashkov, ${ }^{\mathrm{b}}$ \\ Jerry Heath, ${ }^{\mathrm{d}}$ and Wade N. Sisk ${ }^{\mathrm{d}}$
}

\author{
${ }^{a}$ Department of Environmental Science and Technology, Shinshu University \\ 4-17-1 Wakasato, Nagano, Nagano 380-8553, Japan \\ b 2800 Radiant Ave.Radiant Color, Richmond, CA, 94804 \\ ${ }^{\mathrm{c}}$ Institute of Problems of Chemical Physics, Russian Academy of Sciences, \\ 142432 Chernogolovka, Moscow Region, Russian Federation \\ ${ }^{\mathrm{d}}$ Chemistry Department, University of North Carolina at Charlotte \\ 9201 University City Blvd., Charlotte, NC 28223-0001, USA \\ ${ }^{*}$ Corresponding author. Tel: (704) 687-4433, Fax: (704) 687-3151 \\ E-mail:wsisk@uncc.edu
}

\begin{abstract}
Polymer-dispersed perylene di-imide dye photodegradation is investigated by monitoring the fluorescence intensity as a function of $532 \mathrm{~nm}$ laser pulses. Anaerobically irradiated polymer-dye films exhibited an accelerated decrease in fluorescence intensity, which was partially recovered upon exposure to oxygen. Decelerated photodegradation rates were observed for perylene diimide ethanol solutions upon the addition of a singlet oxygen quenching antioxidant. These observations suggest reversible photoreduction and Type II photo-oxidation as important photodegradation mechanisms. Type II photo-oxidation for Perylene Red $532 \mathrm{~nm}$ irradiation is supported by a singlet oxygen quantum yield of $0.09 \pm 0.03$, determined via detection of timeresolved $\mathrm{O}_{2}\left(\mathrm{a}^{1} \Delta_{\mathrm{g}} \rightarrow \mathrm{X}^{3} \Sigma_{\mathrm{g}}{ }^{-}\right)$infrared phosphorescence.
\end{abstract}


OCIS codes: 130.0130, 130.3130, 160.2540, 160.3130, 160.4890.

\section{Introduction}

Polymer-dispersed perylene di-imide dyes (Fig. 1) have found use in optical/optoelectronic applications such as energy transfer dye lasers, ${ }^{1-3}$ solid-state dye lasers, ${ }^{4-6}$ optical amplifiers, ${ }^{7}$ luminescent solar concentrators, ${ }^{8}$ luminescent converters for blue LEDs ${ }^{9}$ and electron transport materials for photovoltaics ${ }^{10-12}$. Of central importance to these applications is the dye photostability. Previous photostability studies of pyrromethene difluoroborate dyes, used in energy transfer dye lasers and solid-state dye lasers, have shown type II photo-oxidation to be the primary mechanism of photodegradation. ${ }^{13-15}$ The perylene di-imide dyes, Perylene Red and Perylene Orange, have demonstrated superior photostability relative to the pyrromethene difluoroborate laser dyes, PM567 and PM597. 4, 6, 14 Methyl methacrylate solutions of Perylene Orange (BASF241) have demonstrated slower photodegradation, measured as a reduction in lasing efficiency, under vacuum relative to ambient conditions for $532 \mathrm{~nm}$ irradiation. ${ }^{14}$ This suggests photo-oxidation as the primary mechanism of photodegradation. Photoreduction of Perylene Orange has also been reported. ${ }^{16}$

(Fig. 1)

In this report the photostability of polymer-dispersed films and solutions of Perylene Orange and Perylene Red laser dyes are investigated for $532 \mathrm{~nm}$ laser irradiation under aerobic and anaerobic conditions to better understand the photodegradation mechanism. Furthermore, the singlet oxygen quantum yield was determined for Perylene Red, in an effort to determine the relative importance of type II photo-oxidation for Perylene Red photodegradation. 


\section{Experimental}

A. Photodegradation measurements

Perylene di-imide dyes were obtained from two sources and used without further purification. Lumogen F Orange 240 (Perylene Orange) and Lumogen F Red 300 (Perylene Red) obtained from BASF had molar masses of 710.873 and 963.956 grams respectively. Perylene Orange and Perylene Red obtained from Exciton has molar masses of 710.87 and 1029.26 grams respectively. Polyester (LR7804 density $1.27 \mathrm{~g} \mathrm{~cm}^{-3}$ ) and poly(methyl methacrylate) (PMMA, average molar mass 120,000) were obtained from Radiant Color and Aldrich Chemical Company respectively. Buckminster fullerene $\left(\mathrm{C}_{60}\right)$ was obtained from Fullerene Enterprises. All of the above chemicals were used without further purification. Thin film samples were fabricated by spin casting (3000 rpm, 30 seconds) dye/polymer/chloroform solutions onto glass microscope

slides. These films were heated to $80^{\circ} \mathrm{C}$ for 20 hours under vacuum. Films composition and thickness values are listed in Table 1.

Table 1. Film composition and thickness

\begin{tabular}{|c|c|c|c|c|}
\hline PMMA/g & Polyester /g & Dye/CHCl ${ }_{3}$ solution & $\begin{array}{c}\text { Volume of dye/CHCl } \\
\text { solution }\end{array}$ & $\begin{array}{c}\text { Thickness } \\
\text { / } \mu \mathrm{m}\end{array}$ \\
\hline & 0.25 & $\begin{array}{c}1.0 \times 10^{-3} \mathrm{M} \\
\text { Lumogen F Red } 300\end{array}$ & 5 & 0.4 \\
\hline & 0.5 & $\begin{array}{c}\quad 6.0 \times 10^{-4} \mathrm{M} \\
\text { Lumogen F Orange } 240\end{array}$ & 5 & 1 \\
\hline 5 & & $\begin{array}{c}1.0 \times 10^{-3} \mathrm{M} \text { Perylene Red } \\
\text { (Exciton) }\end{array}$ & 40 & 2 \\
\hline 5 & & $\begin{array}{c}1.0 \times 10^{-3} \mathrm{M} \text { Perylene } \\
\text { Orange (Exciton) }\end{array}$ & 40 & 2 \\
\hline
\end{tabular}


Photodegradation experiments were carried out by measuring the fluorescence (dye films) or absorbance (dye solutions) following $532 \mathrm{~nm}$ irradiation provided by the second harmonic of a pulsed Nd:YAG laser. The PMMA dispersed dye films cast on glass slides served as planar waveguides for the resulting fluorescence similar to previous studies. ${ }^{17,18}$ The waveguided fluorescence orthogonal to laser propagation was collected via a lens and focused onto the entrance slits of a monochromator. This dispersed emission was detected by a photomultiplier (Hamamatsu R928) tube and recorded via a boxcar integrator. An apparatus shown in Figure 2 was used for thin film fluorescence experiments. The spin cast slide served as a window for this apparatus with the dye polymer film facing inward.

(Fig. 2)

For thin films under vacuum, the films were evacuated for 10 minutes prior to irradiation. A one centimeter cuvette equipped with a cold finger and stopcock was used to measure the absorbance of dye solutions following $532 \mathrm{~nm}$ irradiation. Solution phase samples were deoxygenated by 15 freeze-pump-thaw cycles with liquid nitrogen. This was preferred over nitrogen purging in order to maintain the initial volume of solution, since photodegradation rates are solution dependent.

B. Singlet oxygen quantum yield measurements

Buckminster fullerene $\left(\mathrm{C}_{60}\right)$ was obtained from Fullerene Enterprises and used as purchased. HPLC grade benzene was purchased from Aldrich chemical Co. and used without further purification. 
Samples were irradiated with the second harmonic $(532 \mathrm{~nm})$ of a Nd:YAG laser and the resulting $\mathrm{O}_{2}\left(\mathrm{a}^{1} \Delta_{\mathrm{g}} \rightarrow \mathrm{X}^{3} \Sigma_{\mathrm{g}}{ }^{-}\right)$infrared phosphorescence at $1267 \mathrm{~nm}$ was detected at right angles to the laser propagation. This phosphorescence was filtered by three high pass filters (Rolyn OG5550, 65.1398, 65.1400) and a 1270 nm narrow bandpass filter (Spectrogon Filter N13-1270010-8) and finally imaged on the active element of a high speed ( $\tau \sim 1 \mu \mathrm{s})$ Applied Detector Ge photodiode. Laser fluence values in the range of $0.5-1.4 \mathrm{~mJ} \mathrm{~cm}^{-2}$ pulse $^{-1}$ resulted in a linear laser power dependence. To avoid interference with Perylene Red fluorescence, apparent decay profiles were fit to an exponential decay for two lifetimes after a 20 microsecond delay to ensure fitting of ${ }^{1} \mathrm{O}_{2}$ phosphorescence. Phosphorescence intensities were computed as the value of $\mathrm{c}_{1}-\mathrm{C}_{0}$. Singlet oxygen production quantum yields were obtained from comparing plots of phosphorescence intensity vs. absorbance for benzene solutions of Perylene Red to $\mathrm{C}_{60} /$ benzene solutions. $^{19}$

\section{Results and discussion}

\section{A. Thin film photodegradation}

Figure 3 shows the photodegradation of polyester dispersed Lumogen F Red 300 and Lumogen F Orange 240 films resulting from $532 \mathrm{~nm}$ irradiation under vacuum and ambient conditions. Samples under vacuum exhibited an accelerated decrease of fluorescence relative to samples under an ambient atmosphere. Partial recovery of fluorescence is observed when samples irradiated under vacuum are exposed to the ambient atmosphere. Perylene Red and Perylene Orange PMMA films also demonstrated an accelerated anaerobic photodegradation with partial recovery upon exposure to the ambient atmosphere with cessation of the irradiation as shown in Fig. 4. Egerton et al. observed a similar anaerobic photodegradation and recovery upon oxygen 
exposure for nylon films containing 1-piperidinoanthraquinone. ${ }^{20}$ This was explained by reversible photoreduction. Evidence for perylene di-imides behaving as good electron acceptors is noted by their use as n-type conductors in photovoltaics ${ }^{10-12}$ and their use as photooxidants for various substances via superoxide formation. ${ }^{21-23}$ Thus, reversible photoreduction is suggested as a major component of the anaerobic photodegradation mechanism for the perylene di-imide dyes.

(Fig. 3)

(Fig. 4)

To determine if the photodegradation deceleration observed in the ambient atmosphere is attributed to oxygen, Perylene Red/PMMA films were irradiated under varying oxygen partial pressures. Figure 5 shows decreasing photodegradation rates for Perylene Red and Perylene Orange for increasing oxygen partial pressures. This shows that increased photodegradation under vacuum is attributed to $\mathrm{O}_{2}$ removal. These results are contrary to those of Rahn, in which slower photodegradation of deoxygenated Perylene Orange (BASF241) methyl methacrylate solutions was observed relative to oxygenated solutions. ${ }^{14}$ This difference could be due to the fact that PMMA is a better Lewis base than MMA, typically an electron acceptor due to stabilization via carbanion delocalization upon electron acceptance. ${ }^{24}$ This illustrates the danger in extrapolating photostability results from dye/monomer solutions to polymer-dispersed dyes.

(Fig. 5).

B. Ethanol Solution Photodegradation 
Decreased photodegradation rates for oxygenated PMMA dispersed perylene di-imide dyes relative to deoxygenated samples is attributed to suppression of photoreduction. The presence of high electron affinity $\mathrm{O}_{2}$ suppresses photoreduction by intercepting electrons that would normally reduce the excited state perylene di-imide dyes. Nevertheless, perylene di-imide dye Type II photo-oxidation must be considered. Addition of the singlet oxygen quencher $\mathrm{NaN}_{3}$ is expected to suppress Type II photo-oxidation resulting in increased perylene di-imide photodegradation lifetimes. This predicted increase in photodegradation lifetime is observed in Fig. 6a for $\mathrm{NaN}_{3}$ addition to Perylene Red ethanol solutions under aerobic conditions.

(Fig. 6).

For deoxygenated Perylene Red ethanol solutions addition of $\mathrm{NaN}_{3}$ resulted in accelerated Perylene Red photodegradtion rates shown in Fig. 6b. Exposure of the photodegraded dye solutions to the ambient atmosphere once again resulted partial recovery of dye absorbance. This is consistent with reversible photoreduction proposed for perylene di-imide polymer films. The increased photodegradation rate upon $\mathrm{NaN}_{3}$ addition for deoxygenated solutions is consistent with $\mathrm{N}_{3}{ }^{-}$serving as a source of electrons for photoreduction. This is consistent with anthraquinone triplet state quenching by electron donating inorganic anions ( $\left.\mathrm{X}^{-}\right)$as shown in the scheme below, where D represents anthraquinone dye. ${ }^{20}$

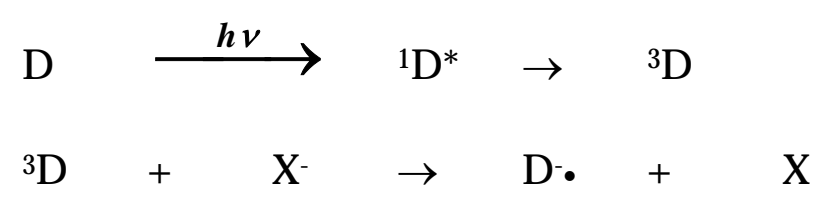

The visible spectra of Perylene Red/ethanol solutions before and after $532 \mathrm{~nm}$ irradiation are shown in Fig. 7. Following irradiation the decrease of the Perylene Red peak at $578 \mathrm{~nm}$ is 
accompanied by the rise of a peak at $793 \mathrm{~nm}$. This new peak is believed to be that of the Perylene Red anion, stabilized by the sodium cation. Gosztola et al. observed absorbance peaks at $526 \mathrm{~nm}$ and $700 \mathrm{~nm}$ for the neutral and anion respectively of a perylene di-imide derivative. ${ }^{25}$ This anionic bathochromic shift is consistent with assigning the new post-photolysis $793 \mathrm{~nm}$ peak to the Perylene Red anion. Exposure of this anaerobically irradiated sample to the ambient atmosphere resulted in a disappearance of the anion peak and partial recovery of the neutral Perylene Red peak. This is believed to occur via the following mechanism.

$$
\begin{aligned}
& \mathrm{O}_{2}+\mathrm{D}^{-}+\rightarrow \mathrm{O}_{2}^{-}+\mathrm{D}^{-} \\
& \mathrm{O}_{2}^{-}+\mathrm{N}_{3}+\rightarrow \mathrm{O}_{2}+\mathrm{N}_{3}^{-}
\end{aligned}
$$

(Fig. 7)

Attempts to reproduce the above results with anaerobic irradiation of Perylene Orange/ $\mathrm{NaN}_{3} /$ ethanol solutions were unsuccessful: the growth of an anion peak was not detected and the Perylene Orange peak recovery was not observed upon exposure of the photolyzed solution to the ambient atmosphere. This is in contrast to anaerobically irradiated Perylene Orange/polymer thin films which exhibited partial recovery upon exposure to the atmosphere. This suggests that reversible photoreduction observed for perylene di-imide polymer films as well as Perylene Red ethanol solutions does not play a role in the photodegradation of Perylene Orange ethanol solutions. Ethanol solutions of Perylene Orange may still undergo irreversible photoreduction.

\section{Singlet oxygen quantum yield}


The relative photostabilization of Perylene Red by $\mathrm{NaN}_{3}$ irradiated under aerobic conditions in Figure 6a suggests quenching of ${ }^{1} \mathrm{O}_{2}$ and/or quenching of the triplet state of Perylene Red by $\mathrm{NaN}_{3}$ according to the Type II photo-oxidation scheme: ${ }^{26}$

$$
\begin{aligned}
& \mathrm{D}+\mathrm{h} v \stackrel{\boldsymbol{k}_{5}}{\longrightarrow}{ }^{1} \mathrm{D}^{*} \\
& { }^{1} \mathrm{D}^{*} \stackrel{\boldsymbol{k}_{6}}{\longrightarrow} \quad \mathrm{D} \quad(+\mathrm{h} v) \\
& \begin{array}{llll}
{ }^{1} \mathrm{D}^{*} & \stackrel{\boldsymbol{k}_{7}}{\longrightarrow} & { }^{3} \mathrm{D} & \\
& { }^{3} \mathrm{D}+\mathrm{NaN}_{3} \stackrel{\boldsymbol{k}_{8}}{\longrightarrow} & \mathrm{D}+\mathrm{NaN}_{3}
\end{array} \\
& { }^{3} \mathrm{D}+{ }^{3} \mathrm{O}_{2} \stackrel{\boldsymbol{k}_{9}}{\longrightarrow} \quad \mathrm{D}+{ }^{1} \mathrm{O}_{2} \\
& { }^{1} \mathrm{O}_{2}+\mathrm{NaN}_{3} \stackrel{\boldsymbol{k}_{10}}{\longrightarrow}{ }^{3} \mathrm{O}_{2}+\mathrm{NaN}_{3} \\
& { }^{1} \mathrm{O}_{2}+\mathrm{D} \stackrel{\boldsymbol{k}_{11}}{\longrightarrow} \text { products } \\
& { }^{1} \mathrm{O}_{2}+\mathrm{D} \stackrel{\boldsymbol{k}_{12}}{\longrightarrow}{ }^{3} \mathrm{O}_{2}+\mathrm{D} \\
& { }^{1} \mathrm{O}_{2} \stackrel{\boldsymbol{k}_{13}}{\longrightarrow} \quad{ }^{3} \mathrm{O}_{2} \quad(+\mathrm{h} v)
\end{aligned}
$$

Direct observation of $\mathrm{O}_{2}\left(\mathrm{a}^{1} \Delta_{\mathrm{g}} \rightarrow \mathrm{X}^{3} \Sigma_{\mathrm{g}}^{-}\right)$time-resolved infrared phosphorescence (Eq. 13) as shown in Fig. 8 bolsters the possibility of the above Type II photo-oxidation mechanism. The infrared phosphorescence was fit to the an exponential of the form:

$$
\text { phosphorescence intensity }=c_{0}+c_{1} \exp \left(-c_{2} \mathrm{t}\right)
$$

To gauge the relative importance of this mechanism the quantum yield of ${ }^{1} \mathrm{O}_{2}$ infrared phosphorescence was determined. 


\section{(Fig. 8)}

Time-resolved ${ }^{1} \mathrm{O}_{2}$ phosphorescence following $532 \mathrm{~nm}\left(1.06 \mathrm{~mJ} \mathrm{~cm}^{-2}\right.$ pulse $\left.{ }^{-1}\right)$ irradiation of $2.1 \times 10^{-5} \mathrm{M}$ Perylene Red in benzene. The solid curve represents the exponential leastsquares fit for a selected region of the phosphorescence decay profile following a $20 \mu$ s delay.

(Fig. 9)

The ratio of the least squares slopes of ${ }^{1} \mathrm{O}_{2}$ phosphorescence vs. absorbance plots shown in Fig. 9 is equal to the ratio of quantum yields, if the same solvent is used. ${ }^{20}$ This results in a singlet oxygen quantum yield of $0.09 \pm 0.03(2 \sigma)$ for Perylene Red. This value is comparable the ${ }^{1} \mathrm{O}_{2}$ quantum yield of 0.09 for the laser dye Pyrromethene 567 in benzene. ${ }^{27}$ Low quantum yields for singlet oxygen are expected, since suitable laser dyes have high fluorescence quantum yields. The higher photostability of the perylene di-imide dyes relative to the pyrromethene dyes may be attributed to a lower singlet oxygen reaction rate constant, $\mathrm{k}_{11}$, for the perylene di-imide dyes relative to the pyrromethene dyes. ${ }^{4,6,14}$

We have recently reported the enhanced photodegradation of Pyrromethene 567 and Pyrromethene 597 by Pyrromethene 546 via electron transfer. ${ }^{28}$ The photoexcited Pyrromethene 567/597 donates an electron to Pyrromethene 546 initiating photodegradation. In that pyrromethene system a competition exists between dye electron donation and ${ }^{1} \mathrm{O}_{2}$ photooxidation. Both Pyrromethene 546 and ${ }^{1} \mathrm{O}_{2}$ withdraw electrons from Pyrromethene 567/597 and electron donation from the excited dye (PM597/567) is dominant under both aerobic and anaerobic conditions. By contrast, the perylene di-imide photodegradation channels are competitive between electron capture, prevailing ender anaerobic conditions, and electron 
donation (photo-oxidation), prevailing under aerobic conditions. Thus electron transfer and type II photo-oxidation contribute to the photodegradation of both pyrromethene and perylene diimide dyes. The primary difference is the higher photoreduction rate of perylene di-imide dyes under anaerobic conditions and higher photo-oxidation rate of pyrromethene dyes under aerobic conditions.

\section{Conclusion}

We have shown that perylene di-imide dye photodegradation consists of both Type II photooxidation and partially reversible photoreduction. Type II photo-oxidation prevails under aerobic conditions, whereas photoreduction predominates under anaerobic conditions. This has ramifications for the operation lifetime of photonic devices incorporating perylene di-imide dyes. Oxygen-free device fabrication and encapsulation is used to extend the operation lifetime of organic photonic devices. ${ }^{29-31}$ This procedure might not be suitable for perylene di-imide optical and/or optoelectronic devices, since the exclusion of oxygen would facilitate the photoreduction mechanism. A better strategy is device fabrication in the ambient environment incorporating ${ }^{1} \mathrm{O}_{2}$ quenchers and/or triplet perylene di-imide dye quenchers to suppress Type II photo-oxidation. Caution must be exercised in incorporating this strategy for optoelectronic devices, since these devices consist of other components in addition to the polymer-dispersed dye phase.

\section{Acknowledgement}

The authors are grateful to Prof. T. Fujii of Shinshu University for his encouragement throughout this work. 


\section{References}

1. T. Nhung, M. Canva, F. Chaput, H. Goudket, G. Roger, A. Brun, D. Manh, N. Hung, and J. Boilot, “Dye energy transfer in xerogel matrices and application to solid-state dye lasers,” Optics Comm. 232, 343-351 (2004).

2. D. Su, Y. Yang, G. Qian, Z. Wang, and M. Wang, “Influence of energy transfer on fluorescence and lasing properties of various laser dyes co-doped in ORMOSILs,” Chem. Phys. Lett. 397, 397-401 (2004).

3. Y. Yang, G. Qian, D. Su, Z. Wang, and M. Wang, "Energy transfer mechanism between laser dyes doped in ORMOSILs,” Chem. Phys. Lett. 402, 389-394 (2005).

4. A. Dubois, M. Canva, A. Brun, F. Chaput, and J. Boilot, "Enhanced photostability of dye molecules trapped in solid xerogel matrixes,” Synthetic Metals 81, 305-308 (1996).

5. Y. Yang, M. Wang, G. Qian, Z. Wang, and X. Fan, "Laser properties and photostabilities of laser dyes doped in ORMOSILs,” Opt. Mat. 24 621-628 (2004).

6. G. Qian, Y. Yang, Z. Wang, C. Yang, Z. Yang, and M. Wang, "Photostability of perylene orange, perylene red and pyrromethene 567 laser dyes in various precursors derived gel glasses,” Chem. Phys. Lett. 368, 555-560 (2003).

7. P. Schlup, G. W. Baxter, and I. T. McKinnie, "Single-mode visible and mid-infrared periodically poled lithium niobate optical parametric oscillator amplified in perylene red doped poly(methyl methacrylate),”Opt. Commun. 184, 225-230 (2000).

8. N. N. Barashkov and O. A. Gunder, Fluorescent Polymers (Ellis Horwood, New York, N.Y., 1994). 
9. M. Tasaki, "Transparent coating member for light-emitting diodes and a fluorescent color light source,” US Pat. 6,319,425, 2001.

10. J. Y. Kim and A. J. Bard, “Organic donor/acceptor heterojunction photovoltaic devices based on zinc phthalocyanine and a liquid crystalline perylene di-imide,” Chem. Phys. Lett. 383, 11-15 (2004).

11. C. W. Tang, “Two-layer organic photovoltaic cell,” Appl. Phy. Lett. 48, 183-185 (1986).

12. G. Horowitz, F. Kouki, P. Spearman, D. Fichou, C. Nogues, X. Pan, and F. Garnier, "Evidence for n-type conduction in a perylene tetracarboxylic di-imide derivative,” Adv. Mater. 8, 242-245 (1996).

13. M. S. Mackey and W. N. Sisk, "Photostability of pyrromethene 567 laser dye solutions via photoluminescence measurements,” Dyes and Pigments 51, 79-85 (2001).

14. M. D. Rahn, T. A. King, A. A. Gorman, I. Hamblett, “_Photostability enhancement of Pyrromethene 567 and Perylene Orange in oxygen-free liquid and solid dye lasers,”Appl. Opt. 36, 5862-5871 (1997).

15. G. Jones II, O. Klueva, S. Kumar, D. Pacheco, "Photochemical and lasing properties of pyrromethene dyes,” in Solid State Lasers X, editor: Richard Scheps, Proc. SPIE-Int. Soc. Opt. Eng. 4267, 24-35 (2001).

16. G. Seybold and G. Wagenblast, "New perylene and violanthrone dyestuffs for fluorescent collectors ,’Dyes Pigments 11, 303-317 (1989).

17. K. Ocka, N. Job, J. Kim, S. Kim, K. Koh, “Thin film optical waveguide type UV sensor using a photochromic molecular device, spirooxazine,” Synthetic Metals 117, 131-133 (2001). 
18. M. C. Castex, C. Olivero, A. Fischer, S. Mousel, J. Michelon, D. Ades, and A. Siove, “Polycarbazoles microcavities: towards plastic blue lasers,” Applied Surface Science 197-198, 822-825 (2002).

19. F. Wilkinson, P. Helman, and A. B. Ross, "Rate constants for the decay and reactions of the lowest electronically excited singlet state of molecular oxygen in solution. An expanded and revised compilation ,” J. Phys. Chem. Ref. Data 24, 663-1021 (1995).

20. N. S. Allen and J. F. McKellar Photochemistry of Dyed And Pigmented Polymers (Applied Science, London, 1980).

21. L. Chen, L. A. Lucia, E. R. Gaillard, H. Icil, S. Icli, and D. G. Whitten, "Photo-oxidation of a Conjugated Diene by an Exciplex Mechanism: Amplification via Radical Chain Reactions in the Perylene Di-imide-Photosensitized Oxidation of $\alpha$-Terpinene,” J. Phys. Chem. A. 102, 9095-9098 (1998).

22. S. Icli, S. Demic, B. Dindar, A. O. Doroshenko, and C. Timur "Photophysical and photochemical properties of a water-soluble perylene di-imide derivative,”J. Photochem. Photobiol. A: Chem. 136, 15-24 (2000).

23. H. Dincalp and S. Icli, "Photosynthesis of rose oxide by concentrated sunlight in the absence of singlet oxygen,” J. Photochem. Photobiol. A: Chem. 141, 147151 (2001).

24. R. T. Morrison and R. N. Boyd, Organic Chemistry, $5^{\text {th }}$ ed. (Allyn and Bacon, inc. Boston, MA. 1987).

25. D. Gosztola, M. P. Niemczyk, W. Svec, A. S. Lukasand, and M. R. Wasielewski, “Excited Doublet States of Electrochemically Generated Aromatic Imide and Di-imide Radical Anions,” J. Phys. Chem. A 104, 6545-6551 (2000). 
26. W. N. Sisk and W. Sanders, "The concentration dependence of the normalized photostability of 1,3,5,7,8-pentamethyl-2,6-di-t-butylpyrromethene-difluoroborate complex (PM597) methanol solutions,” J. Photochem. Photobiol. A: Chem. 167, 185-189 (2004).

27. A. A. Gorman, I. Hamblett, T. A. King, and M. D. Rahn, "A pulse radiolysis and pulsed laser study of the pyrromethene 567 triplet state,” J. Photochem. Photobiol. A: Chem. 130, 127-132 (2000).

28. N. Tanaka and W. N. Sisk, "The photodegradation of pyrromethene 567 and pyrromethene 597 by pyrromethene 546,” J. Photochem. Photobiol., A 172, 109-114 (2005).

29. G. H. Kim, J. Oh, Y. S. Yang, L. Do, and K. S. Suh, "Lamination process encapsulation for longevity of plastic-based organic light-emitting devices,” Thin Solid Films 467, 1- 3 (2004).

30. P. L. Rendu, T. P. Nguyen, and L. Carrois, "Cellulose acetate and PVDC used as protective layers for organic diodes," Synthetic Metals 138, 285-288 (2003).

31. K. M. Kim, B. J. Jang, W. S. Cho, and S. H. Ju, "The property of encapsulation using thin film multi layer for application to organic light emitting device,” Current Applied Physics 5, 64-66 (2005).

\section{Figure Captions}

Fig. 1. Generic perylene di-imide dye structure. 
Fig. 2.

Thin film sample holder (a) O-ring. (b) thin film. (c) glass slide. (d) O-ring joint. (e) O-ring joint. (f) stopcock.

Fig. 3

Normalized fluorescence following $532 \mathrm{~nm}$ irradiation for samples under ambient conditions and vacuum $\bigcirc$. designates the normalized fluorescence for samples exposed to ambient atmosphere for five minutes with no irradiation following irradiation under vacuum. (a) $2.5 \times 10^{-4}$ M Lumogen F Red 300 / polyester (100 mJ cm² pulse $\left.^{-1}, 2 \mathrm{~Hz}\right) \lambda_{\text {obs }}=643 \mathrm{~nm}$ (b) $7.62 \times 10^{-3} \mathrm{M}$ Lumogen F Orange $240 /$ polyester $\left(86 \mathrm{~mJ} \mathrm{~cm}^{-2}\right.$ pulse $\left.^{-1}, 2 \mathrm{~Hz}\right) \lambda_{\text {obs }}=587 \mathrm{~nm}$.

Fig. 4.

Normalized fluorescence following $532 \mathrm{~nm}$ irradiation for samples under ambient conditions and vacuum $\bigcirc$. designates the normalized fluorescence for samples exposed to ambient atmosphere for 5, 10, 15, and 20 minutes with no irradiation following irradiation under vacuum. (a) $1.2 \times 10^{-3}$ M Perylene Red /PMMA (124 mJ cm ${ }^{-2}$ pulse $\left.^{-1}, 10 \mathrm{~Hz}\right) \lambda_{\text {obs }}=602 \mathrm{~nm}$ (b) $1.2 \times 10^{-3}$ M Perylene Orange /PMMA (169 mJ cm pulse $\left.^{-1}, 10 \mathrm{~Hz}\right) \lambda_{\text {obs }}=595 \mathrm{~nm}$.

Fig. 5.

Normalized fluorescence following $532 \mathrm{~nm}$ irradiation for samples under and vacuum $\bullet$, 10 Torr $\mathrm{O}_{2} \mathrm{O}, 50$ Torr $\mathrm{O}_{2} \square$ (Perylene Red) 30 Torr $\mathrm{O}_{2} \square$ (Perylene Orange), and 150 Torr $\mathrm{O}_{2} \Delta$. (a) $1.2 \times 10^{-3}$ M Perylene Red / PMMA (157 $\mathrm{mJ} \mathrm{cm}^{-2}$ pulse $\left.^{-1}, 10 \mathrm{~Hz}\right) \lambda_{\text {obs }}=615 \mathrm{~nm}$ (b) $1.2 \times 10^{-3}$ M Perylene Orange / PMMA (159 mJ cm² pulse $\left.^{-1}, 10 \mathrm{~Hz}\right) \lambda_{\text {obs }}=583 \mathrm{~nm}$. 
Fig. 6.

Normalized absorbance at $578 \mathrm{~nm}$ following $532 \mathrm{~nm}$ irradiation $\left(138 \mathrm{~mJ} \mathrm{~cm}^{-2}\right.$ pulse $\left.^{-1}\right)$ of $3.33 \times 10^{-5} \mathrm{M}$ Perylene Red ethanol solutions devoid of $\mathrm{NaN}_{3}(\square)$ and with $3.33 \times 10^{-4} \mathrm{M} \mathrm{NaN}$ (O)(a) under ambient conditions and (b) under vacuum. designates the normalized absorbance for samples exposed to ambient atmosphere for $0,1,2$, and 3 minutes following irradiation under vacuum. $\mathbf{d}$ designates the normalized absorbance for samples exposed to ambient atmosphere for 1.5, 2.3, 3.3, 4.3 and 5.3 minutes following irradiation under vacuum.

Fig. 7.

Absorbance spectra of $1.67 \times 10^{-5} \mathrm{M}$ Perylene Red / 3.33 $\times 10^{-4} \mathrm{M} \mathrm{NaN}_{3}$ in ethanol: — initial spectrum under vacuum, ${ }^{----}$following 6000 pulses $532 \mathrm{~nm}$ irradiation $\left(138 \mathrm{~mJ} \mathrm{~cm}^{-2}\right.$ pulse $\left.^{-1}\right)$ under vacuum and $\cdots \cdot . \cdot$ exposure of the 6000 pulse irradiated sample to the ambient atmosphere.

Fig. 8.

Time-resolved ${ }^{1} \mathrm{O}_{2}$ phosphorescence following $532 \mathrm{~nm} 1.06 \mathrm{~mJ} \mathrm{~cm}^{-2}$ pulse $^{-1}$ irradiation of $2.1 \times 10^{-5} \mathrm{M}$ Perylene Red in benzene. The solid curve represents the least-squares fit for a selected region of the phosphorescence decay profile following a $20 \mu$ s delay.

Fig. 9.

Initial ${ }^{1} \mathrm{O}_{2}$ phosphorescence intensity vs. absorbance for $\mathrm{C}_{60} /$ benzene $(\mathrm{O})$ and Perylene Red/benzene ( $\square$ ). ----- represents the leastsquares fit. 


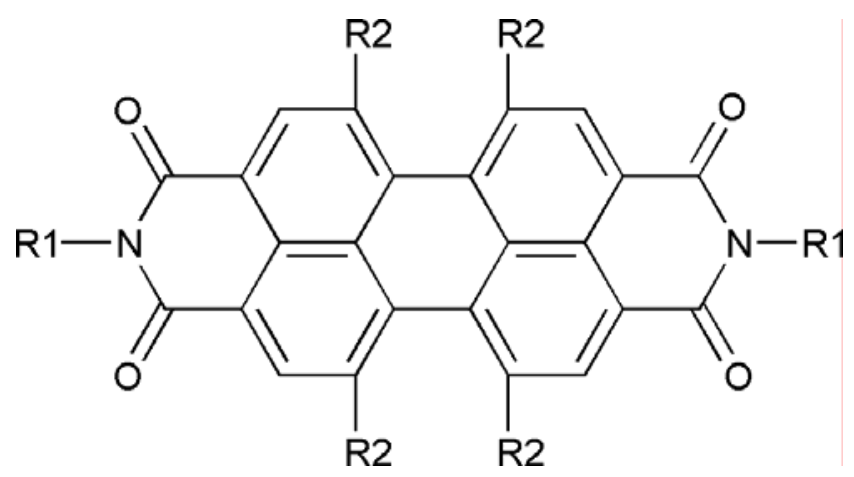

Fig. 1 


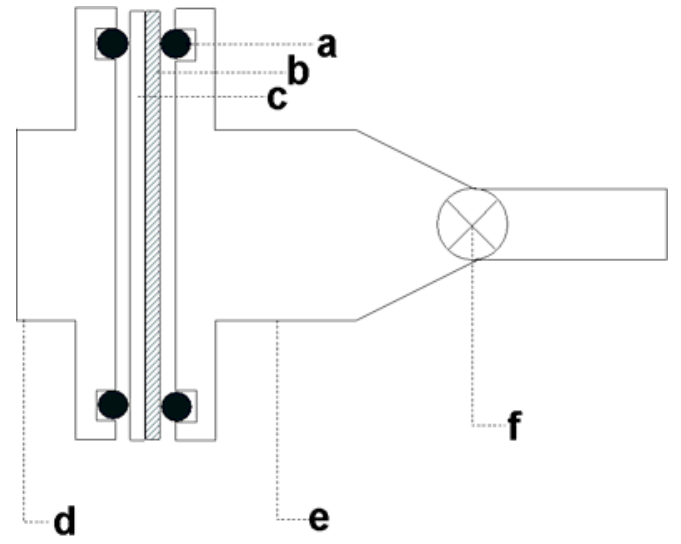

Fig. 2 


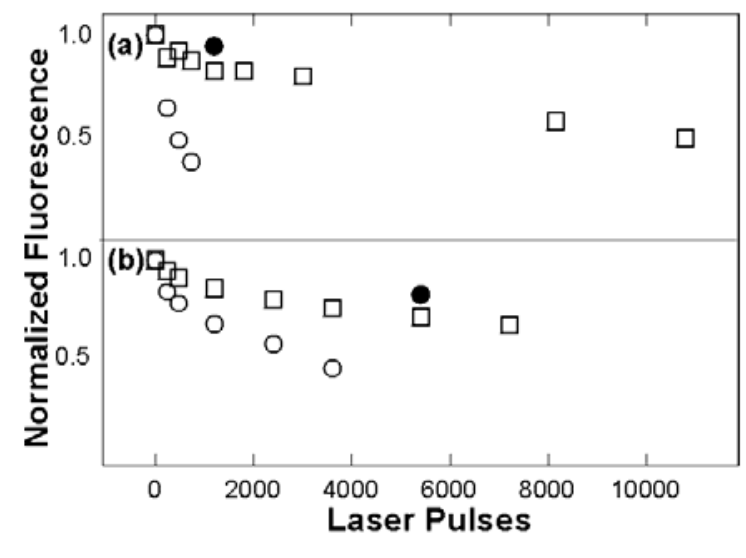

Fig. 3 


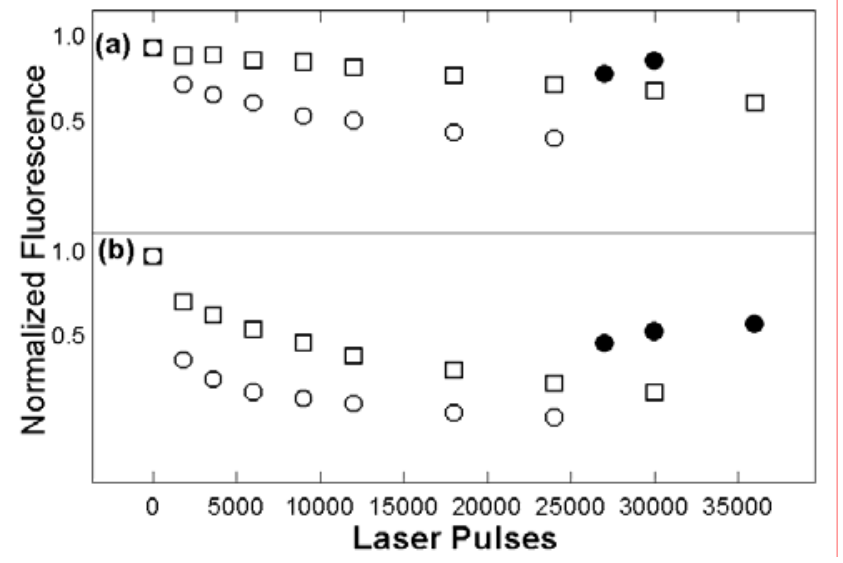

Fig. 4 


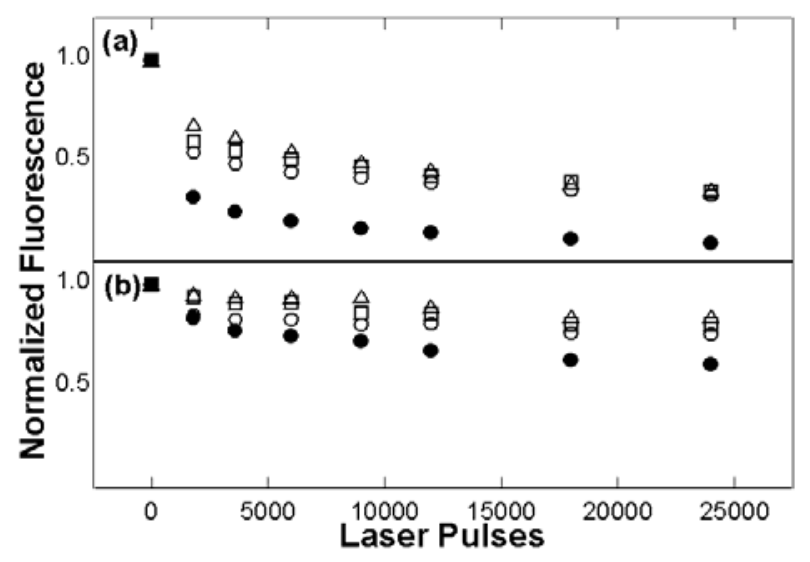

Fig. 5 


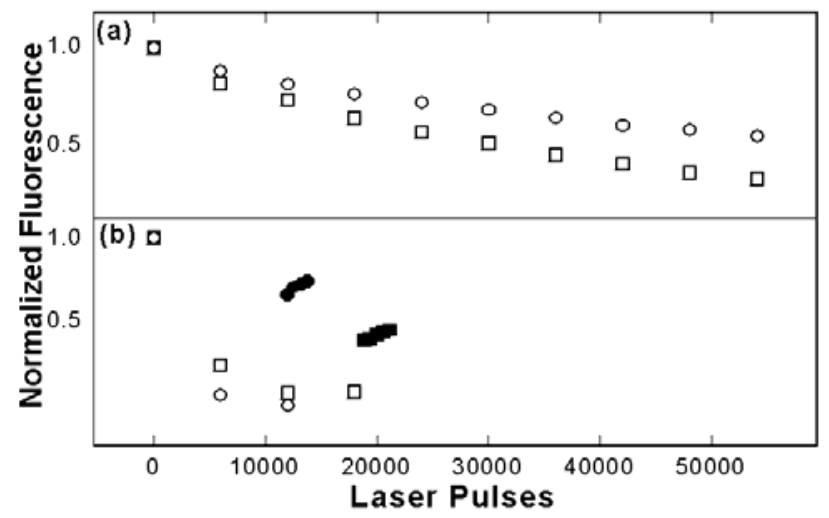

Fig. 6 


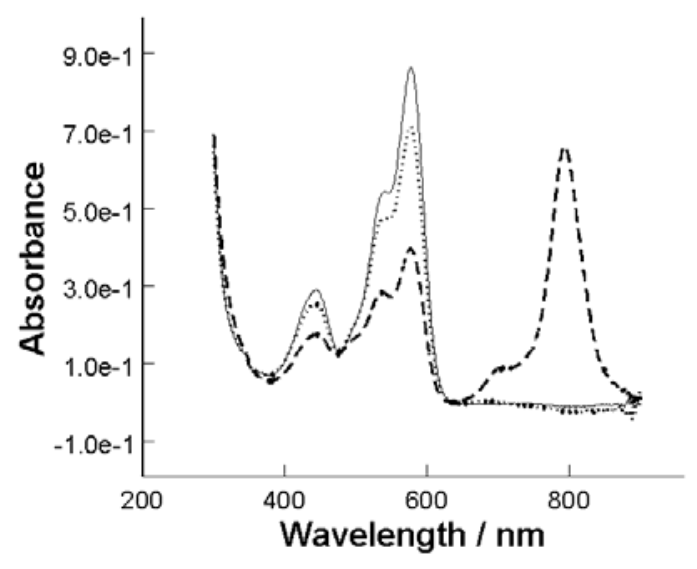

Fig. 7 


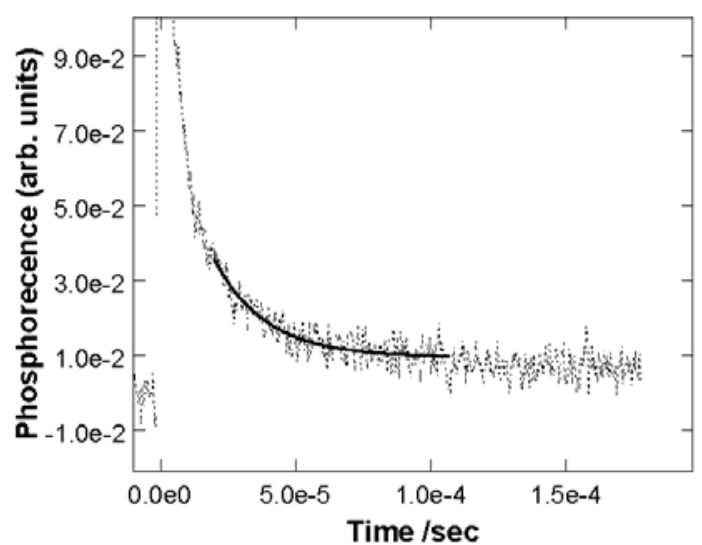

Fig. 8 


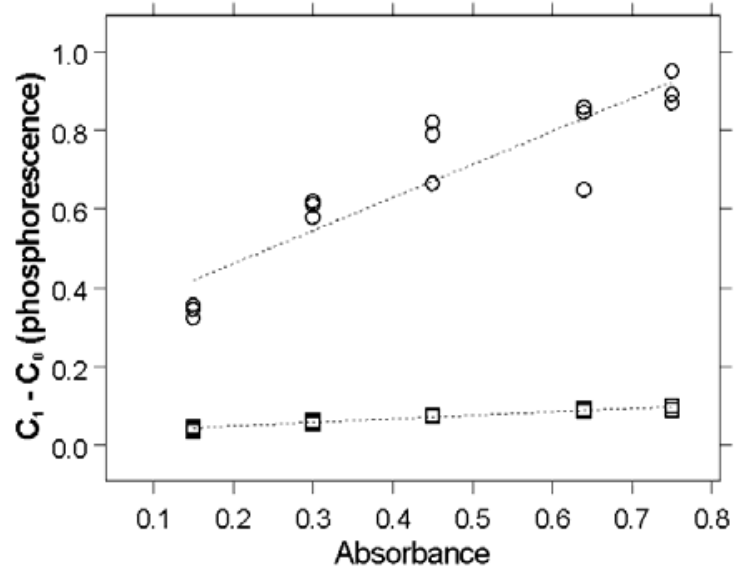

Fig. 9 